\title{
Assessing the role of food quality in the production and hatching of Temora longicornis eggs
}

\author{
Sigrún Huld Jónasdóttir ${ }^{1, *}$, André W. Visser ${ }^{1}$, Carsten Jespersen ${ }^{2}$ \\ ${ }^{1}$ Technical University of Denmark, National Institute of Aquatic Resources (DTU-Aqua), Kavalergaarden 6, \\ 2920 Charlottenlund, Denmark \\ ${ }^{2}$ University of Southern Denmark, Department of Biology, Campusvej 55, 5230 Odense M, Denmark
}

\begin{abstract}
We utilized the varying fatty acid composition of phytoplankton to create 19 different food treatments based on different ratios of 5 potentially important fatty acids and offered these to the copepod Temora longicornis. Egg production and hatching was monitored and related to ingested carbon, dietary fatty acids and the utilization of maternal fatty acid reserves. Egg production rates depended on ingested carbon and the fatty acid 20:5n-3 from the diet and from the female reserves. Hatching success showed a significant dependence on the ingested and maternal fatty acids 22:6n-3, 18:5n-3 and 18:3n-3. Production of nauplii as a combination of egg production and hatching was highly dependent on the fatty acid 22:6n-3 and carbon ingestion. The study confirms the importance of $n-3$ polyunsaturated fatty acids for copepod reproduction and indicates that the female differentially utilizes its fatty acid reserves depending on dietary fatty acid availability during reproduction and that egg production and hatching are dependent on different dietary fatty acids.
\end{abstract}

KEY WORDS: Egg production $\cdot$ Hatching $\cdot$ Food quality $\cdot$ Fatty acid $\cdot$ Temora longicornis

\section{INTRODUCTION}

To date studies on marine copepod nutritional requirements have yielded widely varying results regarding what limits egg production, hatching and ontogenic development. Compounds that have been shown to be potential controlling factors of these growth categories include many different fatty acids, sterols and amino acids. A summary of 20 studies in which fatty acid composition of the potential food was measured along with copepod production (Table 1) shows that a suite of specific fatty acids have been significantly correlated (positively and negatively) with copepod egg production rates (EPR) and hatching success. From this list one can see that one study may find a significant positive relationship between egg production rates and the concentration of a specific dietary fatty acid, while another study might find a negative, or lack of (not listed in Table 1) relationship with the same fatty acid. An example of this is the correlation of EPR with the fatty acid 20:5n-3 in the diet, whereby Broglio et al. (2003) found a positive relation- ship, Arendt et al. (2005) found no correlation, and Koski et al. (2006) reported a negative relationship.

The possible reasons for the inconsistent results are numerous: different zooplankton species may have had different requirements for growth (Hassett 2004), the food concentrations offered have ranged from limiting to super-saturating levels, the lengths of experiments have varied from 1 to $>10 \mathrm{~d}$, and correlations in one study may have been based on food available (Jónasdóttir 1994) and in other studies on food ingested (e.g. Broglio et al. 2003, Dutz et al. 2008). However, the most likely reason for the observed inconsistencies between the investigations is that the different studies might have been dealing with different nutrient limitations, that is, that some limiting component is measured in one study but not in the others. For example, when diatoms are offered as food, the fatty acid 20:5n-3 (EPA) will not be the limiting component, while specific sterols may be limiting (Hassett 2004, Klein Breteler et al. 2005). When the chlorophyte Dunaliella, which totally lacks EPA, is used as food, EPA is always limiting. However, Dunaliella is also 
Table 1. Summary of reported significant correlations between marine copepod egg production rates or egg hatching success and various fatty acids and sterols (including ratios). +: number of studies showing significant positive correlation; -: number of studies showing significant negative correlation; SAFA: sum of saturated fatty acids; MUFA: sum of monounsaturated fatty acids; PUFA: sum of polyunsaturated fatty acids; A: Acartia tonsa, A. hudsonica and/or A. omorii; T: Temora longicornis; C: Calanus finmarchicus and/or C. helgolandicus; P: Pseudocalanus newmani; Sources-1: Støttrup \& Jensen (1990); 2: Jónasdóttir (1994); 3: Ederington et al. (1995); 4: Jónasdóttir et al. (1995); 5: Kleppel \& Burkart (1995); 6: Jónasdóttir \& Kiørboe (1996); 7: Pond et al. (1996); 8: Kleppel et al. (1998); 9: Lee et al. (1999); 10: Jónasdóttir et al. (2002); 11: Broglio et al. (2003); 12: Hazzard \& Kleppel (2003); 13: Shin et al. (2003); 14: Hassett (2004); 15: Crockett \& Hassett (2005); 16: Arendt et al. (2005); 17: Jónasdóttir et al. (2005); 18: Koski et al. (2006); 19: Peters et al. (2007); 20: Evjemo et al. (2008)

\begin{tabular}{|c|c|c|c|c|c|}
\hline \multirow[t]{2}{*}{ Fatty acid/sterol } & \multirow{2}{*}{$\begin{array}{c}\text { Fatty acid } \\
\text { short name }\end{array}$} & \multicolumn{2}{|c|}{ Correlation } & \multirow[t]{2}{*}{ Copepod species } & \multirow[t]{2}{*}{ Source } \\
\hline & & + & - & & \\
\hline \multicolumn{6}{|c|}{ Egg production rates } \\
\hline $14: 0$ & & 3 & & $\mathrm{~A}, \mathrm{~T}, \mathrm{C}$ & 4,7 \\
\hline $16: 0$ & & 2 & & $\mathrm{~T}$ & 18 \\
\hline 18:0 & & 2 & & $\mathrm{~A}, \mathrm{C}$ & 7,8 \\
\hline SAFA & & 1 & & $\mathrm{~T}$ & 16 \\
\hline $16: 1 \mathrm{n}-7$ & & 3 & 2 & $\mathrm{~A}, \mathrm{C}$ & $2,7,10$ \\
\hline $18: 1$ & & 5 & & $\mathrm{~A}, \mathrm{~T}, \mathrm{C}$ & $2,7,19$ \\
\hline MUFA & & 2 & & $\mathrm{~T}, \mathrm{C}$ & 7,16 \\
\hline $16: 2 n-x$ & & 1 & & $\mathrm{C}$ & 10 \\
\hline $18: 2 n-6$ & LA & & 2 & $\mathrm{~A}$ & 4 \\
\hline $18: 3 n-3$ & ALA & 2 & 1 & $\mathrm{~A}, \mathrm{C}$ & $2,12,17$ \\
\hline $18: 4 n-3$ & SDA & 3 & 3 & $\mathrm{~A}, \mathrm{~T}, \mathrm{C}$ & $2,4,13,17$ \\
\hline $18: 5 n-3$ & & 1 & & A & 2 \\
\hline $20: 4 n-6$ & ARA & & & & \\
\hline $20: 5 n-3$ & EPA & 7 & 3 & $\mathrm{~A}, \mathrm{P}, \mathrm{C}, \mathrm{T}$ & $2,3,7,8,10,11,16,17,18,19$ \\
\hline $22: 6 n-3$ & DHA & 8 & 1 & $\mathrm{~A}, \mathrm{~T}, \mathrm{C}$ & $2,4,7,11,13,20$ \\
\hline PUFA & & 3 & & A, C & 7,10 \\
\hline Total fatty acids & & 3 & & A, T, C & $2,7,16$ \\
\hline$n-6$ series & & 2 & 2 & $\mathrm{~A}, \mathrm{~T}$ & 4 \\
\hline$n-3$ series & & 2 & & A & 2 \\
\hline$n-3 / n-6$ & & 4 & 2 & $\mathrm{~A}, \mathrm{~T}, \mathrm{C}$ & $2,4,6,7$ \\
\hline $22: 6 n-3 / 20: 5 n-3$ & DHA/EPA & 6 & 2 & $\mathrm{~A}, \mathrm{~T}$ & $1,2,4,6,19$ \\
\hline $16: 1 n-7 / 16: 0$ & & 1 & 1 & $\mathrm{~T}, \mathrm{C}$ & 10,16 \\
\hline Cholesterol & & 4 & & A, C & 14,15 \\
\hline \multicolumn{6}{|l|}{ Hatching } \\
\hline $14: 0$ & & & 1 & $\mathrm{C}$ & 10 \\
\hline $16: 0$ & & & 2 & $\mathrm{C}$ & 10 \\
\hline $18: 0$ & & & 1 & $\mathrm{~A}, \mathrm{C}$ & 6,10 \\
\hline SAFA & & & 3 & $\mathrm{~A}, \mathrm{C}, \mathrm{T}$ & $10,16,19$ \\
\hline $16: 1 n-7$ & & & 1 & $\mathrm{C}$ & 10 \\
\hline $18: 1$ & & 1 & 3 & $\mathrm{~A}, \mathrm{C}, \mathrm{T}$ & $6,10,16$ \\
\hline MUFA & & 2 & & $\mathrm{~A}, \mathrm{C}$ & 5,7 \\
\hline $16: 2 n-x$ & & 3 & & $\mathrm{~A}, \mathrm{P}, \mathrm{C}$ & $5,9,17$ \\
\hline $18: 2 n-6$ & & 3 & & $\mathrm{~A}, \mathrm{P}, \mathrm{C}$ & $5,9,17$ \\
\hline $18: 3 n-3$ & & 1 & & $\mathrm{C}$ & 7 \\
\hline $18: 4 n-3$ & & 2 & 1 & $\mathrm{~T}$ & 16,18 \\
\hline $18: 5 n-3$ & & 4 & & $\mathrm{~A}, \mathrm{P}, \mathrm{T}, \mathrm{C}$ & $5,9,16,17$ \\
\hline \multicolumn{6}{|l|}{$20: 4 n-6$} \\
\hline \multicolumn{6}{|l|}{$20: 5 n-3$} \\
\hline \multicolumn{6}{|l|}{$22: 6 n-3$} \\
\hline PUFA & & 1 & & A & 3,11 \\
\hline \multicolumn{6}{|l|}{$\begin{array}{l}\text { Total fatty acids } \\
\text { n- } 6 \text { series }\end{array}$} \\
\hline \multicolumn{6}{|l|}{$\begin{array}{l}\text { n-6 serles } \\
n-3 \text { series }\end{array}$} \\
\hline$n-3 / n-6$ & & 3 & 1 & $\mathrm{~A}, \mathrm{C}, \mathrm{T}$ & $6,7,11,13$ \\
\hline $22: 6 n-3 / 20: 5 n-3$ & & 6 & & $\mathrm{~A}, \mathrm{~T}$ & $6,11,16,19$ \\
\hline $16: 1 n-7 / 16: 0$ & & & 1 & $\mathrm{~T}$ & 16 \\
\hline Cholesterol & & 1 & & A & 14 \\
\hline
\end{tabular}

deficient in other essential components, such as other long-chain polyunsaturated fatty acids (PUFAs) and essential sterols (Klein Breteler et al. 1999). Therefore, artificially adding EPA to a Dunaliella diet will not reveal an improvement in growth as the other essential components will still limit growth. Thus, studies with a variable availability of nutritional components have the best potential in helping us to understand how 
dietary nutrient composition affects production and growth.

Another potentially important factor in nutritional studies is the ability of the female to channel stored body reserves into production. Some copepod species have a better ability to store body reserves than others (Evjemo et al. 2003), and the utilization of body reserves for egg production also appears to be species specific (Hassett 2006). This ability to channel stored nutritional elements or compounds, such as nitrogen, fatty acids and sterols, towards egg production and growth is often not considered in copepod nutritional studies.

The goal of the present study was to better differentiate the role of certain fatty acids in the reproduction of marine copepods. We specifically tested several PUFAs, naturally occurring in phytoplankton at different ratios, and related the ingested fatty acids to the egg production and hatching success of the copepod Temora longicornis. The choice of the phytoplankton species used in the experiments was based on 2 criteria. Firstly, they were selected according their ratios of the fatty acids $18: 3 n-3,18: 5 n-3,20: 4 n-6,20: 5 n-3$ and $22: 6 n-3$. All of these fatty acids have previously been shown to be of some nutritional importance in reproductive growth (Table 1). The second criterion was to select phytoplankton types that had, in previous studies, been shown to result in mediocre reproduction success, indicating that they lacked one or more nutritional compounds for copepod reproduction. We present results from a statistical model with the underlying premise that certain dietary compounds control both the rate at which copepods produce eggs and the success rate at which they eventually hatch into nauplii. A portion of these dietary compounds comes immediately from the copepod's diet, while others are obtained from the female's internal reserves. Conceptually, we treat the female as a reservoir of various dietary components that is continually topped up by ingestion and emptied by the production of new eggs.

\section{MATERIALS AND METHODS}

Copepods. Experiments were conducted using the calanoid copepod Temora longicornis originally obtained from the central North Sea but cultured at the DTU-Aqua laboratory for over a year. The cultures were kept at about $15^{\circ} \mathrm{C}$ in the dark and maintained on a mixture of the cryptophyte Rhodomonas sp., the diatom Thalassiosira weissflogii and the dinoflagellate Heterocapsa triquetra at a concentration of ca. $400 \mu \mathrm{g}$ $\mathrm{Cl}^{-1}$. Three weeks prior to the experiments, a new culture was started with the naupliar stages only. This ensured that at the time of the experiment the females were at the same age, and also ensured that females were in the same condition between experiments.

Phytoplankton. The phytoplankton used in the experiments were the diatoms Thalassiosira weissflogii (TW) and Leptocylindricus danicus (LD); the chlorophyte Dunaliella tertriolecta (DT); the prasinophyte Tetraselmis suecica (TS); and the dinoflagellates Amphidinium carterii (AC) and Heterocapsa triquetra (HT).

Phytoplankton was grown at $18^{\circ} \mathrm{C}$ in 1 to 21 batch cultures and B1 medium (Hansen 1989) with silica added to the diatom cultures. The cultures were exposed to an irradiance of $100 \mu \mathrm{mol}$ photons $\mathrm{m}^{-2} \mathrm{~s}^{-1}$ in a 16:8 h light:dark cycle. The algae were kept in the exponential growth phase by daily dilutions of the culture. Cell densities were estimated by cell counts of a minimum of 300 cells using Sedgwidge-Rafter counting chambers. Average algal cell volumes were measured using a Coulter Counter with the exception of LD for which length and width of $>50$ cells were measured using an inverted microscope. Cell concentrations were converted to carbon using the volumebased size according to Menden-Deuer \& Lessard (2000). Sizes, fatty acid and carbon content of the phytoplankton are listed in Table 2.

Experiments. Six sets of experiments were conducted, each with a series of phytoplankton mixtures as shown in Table 3. Each food suspension was adjusted to a final concentration of ca. $250 \mu \mathrm{g} \mathrm{C} \mathrm{l^{-1 }}$ (actual range in all experiments from 225 to $276 \mu \mathrm{g} \mathrm{C}$ $\mathrm{l}^{-1}$ ). Then, 13 mixture experiments and 12 single-diet experiments were carried out. As 4 of the single diets were repeated in some of the sets (TW [2], DT [3], LD [3], TS [2]) this resulted in 19 different food treatments.

Ten females and 3 males were put into $630 \mathrm{ml}$ experimental bottles with the food suspensions. Each treatment was run with 5 replicates. The bottles were sealed without head space and placed on a rotating (1 rpm) plankton wheel. The experiment was run for $9 \mathrm{~d}$ at $15^{\circ} \mathrm{C}$ in darkness. To avoid the potential negative effect of the experimental food on the sperm quality (Ianora et al. 1999), the males were replaced each day with new ones from the stock culture. Consequently, the fertilization potential of the produced eggs was kept the same among all treatments and throughout the experiment. Each day, new food suspensions were made, females and eggs were gently sieved out of the previous suspension (with 180 and $64 \mu \mathrm{m}$ sieves, respectively) and counted, and females were put into fresh food suspensions. Empty egg membranes were also counted to account for cannibalized eggs. After Days 2, 6 and 9, eggs from each food treatment were checked for hatching. The eggs from the 5 replicate experimental bottles were pooled into one $630 \mathrm{ml}$ bottle containing $0.2 \mu \mathrm{m}$ filtered seawater; the bottle was sealed without headspace and placed on the rotating 
Table 2. Characteristics of the phytoplankton: fatty acid and carbon content (pg cell ${ }^{-1}, \pm 1 \mathrm{SE}$ ), size $\left(\mu \mathrm{m}^{3}\right)$ and percent of total fatty acids in carbon content. Total FAs: sum of all fatty acids; SAFA: saturated fatty acids; MUFA: monounsaturated fatty acids; PUFA: polyunsaturated fatty acids. The fatty acids 18:3n-3 (ALA), 18:5n-3, 20:4n-6 (ARA), 20:5n-3 (EPA) and 22:6n-3 (DHA) used in our analysis are given in bold print. Fatty acid data for TW calculated from Arendt et al. (2005); carbon content calculated from volume after Menden-Deuer \& Lessard (2000)

\begin{tabular}{|c|c|c|c|c|c|c|}
\hline & $\begin{array}{c}\text { Thalassiosira } \\
\text { weissflogii } \\
\text { (TW) }\end{array}$ & $\begin{array}{c}\text { Leptocylidricus } \\
\text { danicus } \\
\text { (LD) }\end{array}$ & $\begin{array}{c}\text { Dunaliella } \\
\text { tertriolecta } \\
\text { (DT) }\end{array}$ & $\begin{array}{l}\text { Tetraselmis } \\
\text { suecica } \\
\text { (TS) }\end{array}$ & $\begin{array}{c}\text { Amphidinium } \\
\text { carteri } \\
\text { (AC) }\end{array}$ & $\begin{array}{c}\text { Heterocapsa } \\
\text { triquetra } \\
\text { (HT) }\end{array}$ \\
\hline $14: 0$ & 0.93 & $0.95 \pm 0.33$ & $0.01 \pm 0.01$ & $0.02 \pm 0.01$ & $0.99 \pm 0.31$ & $4.17 \pm 1.44$ \\
\hline $16: 0$ & 2.16 & $0.63 \pm 0.18$ & $1.02 \pm 0.28$ & $1.45 \pm 0.34$ & $6.53 \pm 1.32$ & $7.24 \pm 2.47$ \\
\hline 18:0 & 0.38 & $0.01 \pm 0.01$ & $0.01 \pm 0.01$ & $0.01 \pm 0.01$ & $0.84 \pm 0.18$ & $0.20 \pm 0.16$ \\
\hline $20: 0$ & 0.22 & $0.01 \pm 0.004$ & $0.01 \pm 0.32$ & $0.06 \pm 0.03$ & $0.77 \pm 0.21$ & $0.18 \pm 0.18$ \\
\hline SAFA & 3.44 & $1.60 \pm 0.51$ & $1.05 \pm 0.30$ & $1.54 \pm 0.35$ & $9.12 \pm 1.65$ & $11.79 \pm 3.86$ \\
\hline $16: 1 \mathrm{n}-7$ & 1.61 & $1.67 \pm 0.56$ & $0.03 \pm 0.01$ & $0.06 \pm 0.02$ & $0.76 \pm 0.24$ & $0.38 \pm 0.04$ \\
\hline $18: 1 n-9$ & 0.48 & $0.10 \pm 0.03$ & $0.16 \pm 0.03$ & $0.44 \pm 0.08$ & $0.43 \pm 0.13$ & $0.35 \pm 0.18$ \\
\hline $18: 1 n-7$ & & $0.29 \pm 0.04$ & $0.04 \pm 0.02$ & $0.20 \pm 0.08$ & $0.21 \pm 0.12$ & $0.06 \pm 0.03$ \\
\hline MUFA & 2.41 & $1.67 \pm 1.18$ & $0.03 \pm 0.01$ & $0.11 \pm 0.02$ & $0.76 \pm 0.24$ & $0.38 \pm 0.04$ \\
\hline $16: 2 n-4$ & 0.00 & $0.61 \pm 0.28$ & $0.05 \pm 0.01$ & $0.02 \pm 0.01$ & $0.02 \pm 0.01$ & \\
\hline $16: 3 n-4$ & 0.04 & $1.18 \pm 0.62$ & & & & \\
\hline $16: 3 n-6$ & & & $0.20 \pm 0.04$ & $0.05 \pm 0.01$ & & \\
\hline $16: 4 n-3$ & & & $0.88 \pm 0.18$ & $1.44 \pm 0.36$ & & \\
\hline $16: 4 n-1$ & & $0.15 \pm 0.07$ & & & & \\
\hline $18: 2 n-6$ & 0.18 & $0.01 \pm 0.01$ & $0.28 \pm 0.05$ & $0.08 \pm 0.02$ & $0.03 \pm 0.03$ & $0.44 \pm 0.17$ \\
\hline $18: 3 n-6$ & & $0.03 \pm 0.02$ & $0.05 \pm 0.04$ & & & \\
\hline 18:3n-3 ALA & 0.14 & & $2.01 \pm 0.32$ & $0.95 \pm 0.24$ & & $1.03 \pm 0.25$ \\
\hline $18: 4 n-3$ & 0.15 & $0.02 \pm 0.004$ & $0.02 \pm 0.04$ & $0.43 \pm 0.16$ & $0.97 \pm 0.14$ & $1.95 \pm 0.34$ \\
\hline $18: 5 n-3$ & 0.02 & & & $0.13 \pm 0.04$ & & $2.42 \pm 0.52$ \\
\hline 20:4n-6 ARA & 0.08 & $0.33 \pm 0.14$ & & & & \\
\hline 20:5n-3 EPA & 0.81 & $0.13 \pm 0.06$ & & $0.04 \pm 0.02$ & $0.01 \pm 0.003$ & \\
\hline 22:6n-3 DHA & 0.18 & & & & $0.29 \pm 0.08$ & $1.03 \pm 0.35$ \\
\hline PUFA & 2.06 & $2.47 \pm 1.18$ & $3.49 \pm 0.62$ & $3.13 \pm 0.84$ & $1.31 \pm 0.18$ & $6.87 \pm 0.94$ \\
\hline Total FAs & 9.64 & $6.37 \pm 2.36$ & $4.99 \pm 1.00$ & $5.80 \pm 1.27$ & $14.82 \pm 2.73$ & $22.10 \pm 3.10$ \\
\hline Other FAs & 0.80 & $0.24 \pm 0.10$ & $0.22 \pm 0.05$ & $0.37 \pm 0.07$ & $2.99 \pm 1.06$ & $2.64 \pm 0.23$ \\
\hline Carbon (pg cell ${ }^{-1}$ ) & 76 & 59 & 29 & 56 & 190 & 325 \\
\hline Volume $\left(\mu \mathrm{m}^{3}\right)$ & 878 & 716 & 262 & 353 & 764 & 1472 \\
\hline$\%$ FA of total C & 12.7 & 10.8 & 17.2 & 10.4 & 7.8 & 6.8 \\
\hline
\end{tabular}

plankton wheel. After $72 \mathrm{~h}$ the content of the bottle was fixed, and hatched nauplii were counted.

Ingestion rates were estimated on Days 3 to 4 and 7 to 8 . In addition to the experimental bottles, 3 control bottles without females or males were added to the series of each of the food treatments, and initial concentrations were recorded. These bottles were also put on the plankton wheel for $24 \mathrm{~h}$. Cell concentrations in each bottle were counted $24 \mathrm{~h}$ later, and ingestion rates were calculated according to Frost (1972). For the mixtures, the food selection index $\alpha$ was calculated (Chesson 1983). This index relates the ingestion of the different phytoplankton cells to their abundance, where, for a 2 species mixture, $\alpha=0.5$ indicates no selection (Chesson 1978). One-sample $t$-tests (SPSS) were used to test for significant deviations of $\alpha$ from 0.5 (no selection).
At the end of each experiment (Day 9) the prosome lengths of the females were measured with a dissection microscope using a calibrated ocular stage micrometer. A female carbon content of $8.25 \mu \mathrm{g} C$ was assumed based on the average female carbon content measured on 2 occasions from the same copepod cultures over a 1 yr period (M. Koski pers. comm.).

Chemical analysis. At 2 dates during the 9 d experiment, samples from the phytoplankton cultures were taken for fatty acid analysis. A triplicate sample of each culture ( $>500 \mu \mathrm{g} \mathrm{C}$ ) was filtered onto pre-combusted GF/F filters. In addition, at the termination of the experiments, the females from each treatment were pooled and analysed for fatty acid content ( 26 to 40 females sample ${ }^{-1}$ ). Similarly, $3 \times 40$ females from the stock culture were analysed to attain the initial fatty acid composition of the females. Samples were stored at $-80^{\circ} \mathrm{C}$ until analysed. 
Table 3. Specifics of the 19 treatments. Carbon and fatty acid compositions in the 19 treatments offered. Phytoplankton treatment (abbreviations as in Table 2) followed by the carbon-based percent ratio of the phytoplankton type in the mixture. Carbon, total fatty acid (FA) and polyunsaturated fatty acid (PUFA) concentrations $\left(\mu \mathrm{g} \mathrm{l} \mathrm{l}^{-1}, \pm 1 \mathrm{SE}\right)$

\begin{tabular}{|c|c|c|c|c|c|}
\hline Expt & No. & $\begin{array}{l}\text { Treatment } \\
\text { Phytoplankton }\end{array}$ & Carbon & Total FA & Total PUFA \\
\hline 1,2 & 1 & TW100 & $258 \pm 10$ & $36 \pm 0.1$ & $8 \pm 0.03$ \\
\hline 1 & 2 & TW66/DT33 & $250 \pm 16$ & $37 \pm 2.2$ & $15 \pm 0.7$ \\
\hline 1 & 3 & TW33/DT66 & $230 \pm 9$ & $36 \pm 1.3$ & $22 \pm 0.8$ \\
\hline $1,3,6$ & 4 & DT100 & $248 \pm 3$ & $40 \pm 0.8$ & $30 \pm 0.3$ \\
\hline 2 & 5 & TW75/LD25 & $260 \pm 10$ & $32 \pm 1.2$ & $8 \pm 0.4$ \\
\hline 2 & 6 & TW50/LD50 & $250 \pm 16$ & $27 \pm 2.4$ & $8 \pm 0.4$ \\
\hline 2 & 7 & TW25/LD75 & $239 \pm 3$ & $28 \pm 0.4$ & $9 \pm 0.1$ \\
\hline $2,3,4$ & 8 & LD100 & $251 \pm 4$ & $27 \pm 0.5$ & $10 \pm 1.0$ \\
\hline 3 & 9 & LD66/DT33 & $247 \pm 4$ & $30 \pm 0.5$ & $18 \pm 0.2$ \\
\hline 3 & 10 & LD33/DT66 & $260 \pm 17$ & $37 \pm 1.8$ & $25 \pm 0.7$ \\
\hline 4,5 & 11 & TS100 & $249 \pm 4$ & $21 \pm 1.1$ & $13 \pm 0.2$ \\
\hline 4 & 12 & TS66/LD33 & $238 \pm 6$ & $23 \pm 0.7$ & $11 \pm 0.2$ \\
\hline 4 & 13 & TS33/LD66 & $260 \pm 14$ & $25 \pm 1.3$ & $9 \pm 0.6$ \\
\hline 5 & 14 & TS66/AC33 & $253 \pm 4$ & $21 \pm 0.5$ & $9 \pm 0.4$ \\
\hline 5 & 15 & TS33/AC66 & $250 \pm 0.4$ & $18 \pm 0.03$ & $6 \pm 0.01$ \\
\hline 5 & 16 & $\mathrm{AC} 100$ & $238 \pm 15$ & $15 \pm 0.9$ & $2 \pm 0.1$ \\
\hline 6 & 17 & HT100 & $260 \pm 1$ & $15 \pm 0.03$ & $5 \pm 0.01$ \\
\hline 6 & 18 & HT66/DT33 & $250 \pm 13$ & $25 \pm 1.1$ & $14 \pm 0.6$ \\
\hline 6 & 19 & HT33/DT66 & $247 \pm 4$ & $35 \pm 0.5$ & $21 \pm 0.3$ \\
\hline
\end{tabular}

acids of interest) that is continually recharged by ingestion and emptied by the production of eggs. That is:

$$
\frac{\mathrm{d} \mathbf{A}}{\mathrm{d} t}=\mathbf{I} \cdot \mathbf{A}_{\mathrm{f}}-E_{\mathrm{r}} \mathbf{A}_{\mathrm{e}}
$$

where $\mathbf{A}$ is a vector representing the various compounds in the female, $\mathbf{A}_{\mathrm{f}}$ represents the compounds in the food, and $\mathbf{A}_{\mathrm{e}}$ represents these compounds in the eggs. The vector I represents the ingestion rate of each compound, and $E_{\mathrm{r}}$ is the egg production. Integrating over time gives:

$$
\mathbf{A}(t)-\mathbf{A}(0)=\left(\mathbf{I} \cdot \mathbf{A}_{\mathrm{f}}-E_{\mathrm{r}} \mathbf{A}_{\mathrm{e}}\right) t
$$

While there are doubtless other loss terms, we can use the vector quantity

$$
\mathbf{P}=\mathbf{I} \cdot \mathbf{A}_{\mathrm{f}} t+\mathbf{A}(0)-\mathbf{A}(t)
$$

to indicate the potential contribution of various compounds in influencing egg quantity and quality from both maternal and dietary sources.

A forward, stepwise regression of the elements of $\mathbf{P}$, as well as total ingested $\mathrm{C}$, was performed against

Fatty acid analysis was conducted according to the method described by Klein Breteler et al. (1999). The samples were extracted in $\mathrm{KOH}: \mathrm{MeOH}$, including a known amount of an internal standard (23:0), and saponified for $35 \mathrm{~min}$ at $85^{\circ} \mathrm{C}$. After acidification of the sample to $\mathrm{pH} 3$, double-distilled water, $\mathrm{MeOH}$ and dichloromethane were added. The sample was treated with ultrasound, and the lipid fraction was drawn off and passed through a $\mathrm{NaSO}_{4}$ column to remove all traces of water. Samples were transmethylated using $\mathrm{BF}_{3}$ to form fatty acid methyl esters (FAME), eluted over a silica column with ethyl acetate, and subsequently analysed on a gas chromatograph-mass spectrometer (GC-MS, Agilent 6890 with PTV inlet and Agilent 5973 mass selective detector) on an Agilent DB23 $(60 \mathrm{~m} \times 0.25 \mathrm{~mm}$ ) column using helium as carrier gas. Retention times were compared to those of known FAME mixtures (Matreya PUFA3, SUPELCO 18919 and an extract from the dinoflagellate Prorocentrum minimum to locate the 18:5n-3 fatty acid).

Model calculations. The underlying premise for a food-quality model is that certain dietary compounds control both the rate at which copepods produce eggs and the success rate at which they eventually hatch into nauplii. Some quantity of these dietary compounds comes immediately from the copepod's diet, while other quantities are stored and can be released from the female's reserves. In this model, we treat the female as a reservoir of various dietary components (the 5 fatty total egg production (EP, Days 3 to 9), total nauplii production (NP, Days 3 to 9) and the percent of hatching success (Day 9) using SPSS. The forward, stepwise regression seeks the best possible statistical model, by successively introducing variables into a multiple regression. The $F$-value for a new variable to be entered into the regression was set at 4.0, essentially equal to a p-value of 0.06 . Five different dietary components were tested. In order to fulfil the constancy of variance requirement, hatching success values (in \%) were arcsine and log transformed prior to analysis.

\section{RESULTS}

The experiments were carried out over a 1 yr period, from March 2005 to March 2006, and tested to determine if the performance of the females was different in the experiments over time. Egg production rates (EPR) measured after the first incubation day of acclimation on the non-mixed diets $(100 \%)$ showed no significant differences in average EPRs between the 6 experiments (2-way ANOVA: $F_{5,5}=1.76, \mathrm{p}=0.15$ ). It can be said with confidence that the different generations of cultured females were not performing differently over the period of the experiment.

Female size did not differ between the experiments $\left(\right.$ mean $\pm \mathrm{SD}: 1.027 \pm 0.008 \mathrm{~mm}, 1$-way ANOVA, $F_{23}=$ $1.11, \mathrm{p}=0.32$ ). 


\section{Ingestion rates}

Temora longicornis ingested 7 to $70 \%$ of its body carbon per day, with the lowest value observed when Dunaliella tertriolecta was used as food (Fig. 1). There was a significant difference between the treatments in carbon-specific ingestion (1-way ANOVA, $F_{24}=23.58$,
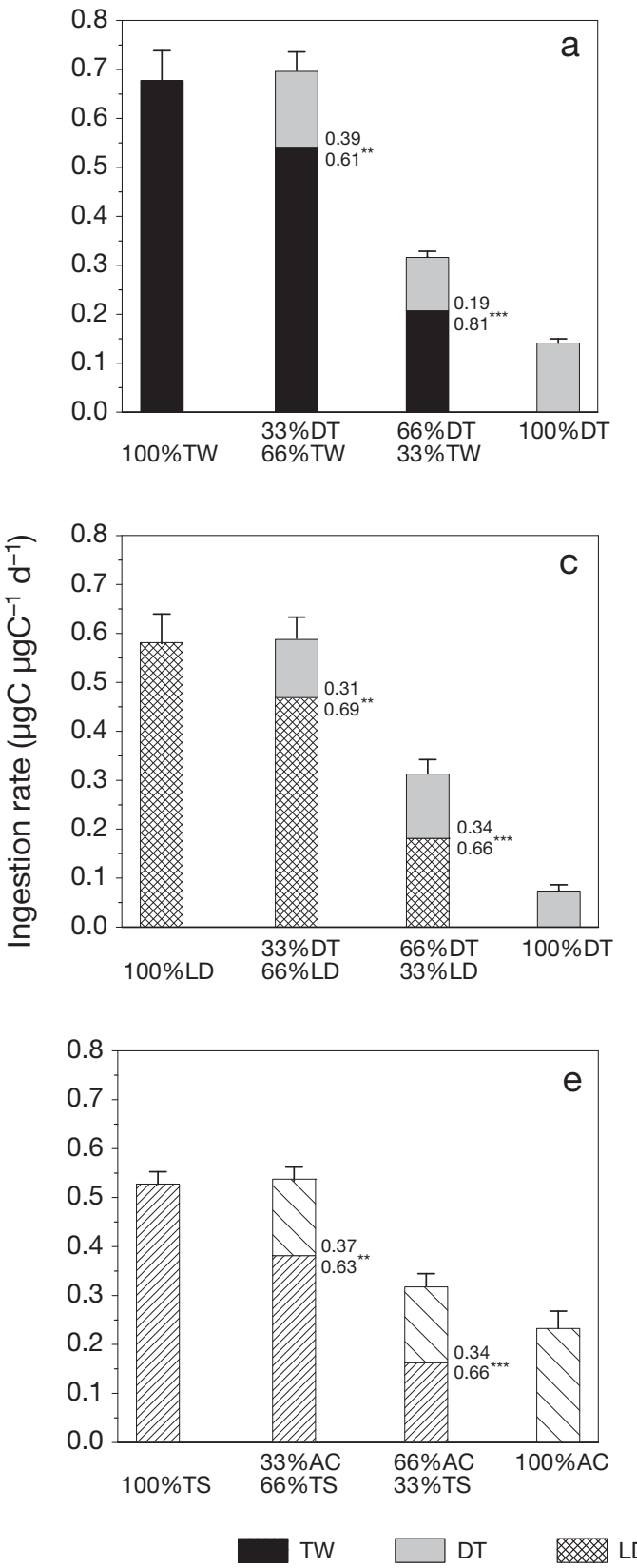

$p<0.001$ ), with the lowest ingestion rates being significantly different from the highest (results from 171 pairwise comparisons using the Holm-Sidak post hoc method). The results from $t$-tests on the difference of the measured selection index $\alpha$ from 0.5 are shown next to the bars of the mixed diets in Fig. 1. D. tertriolecta was not ingested at high rates or in proportion to
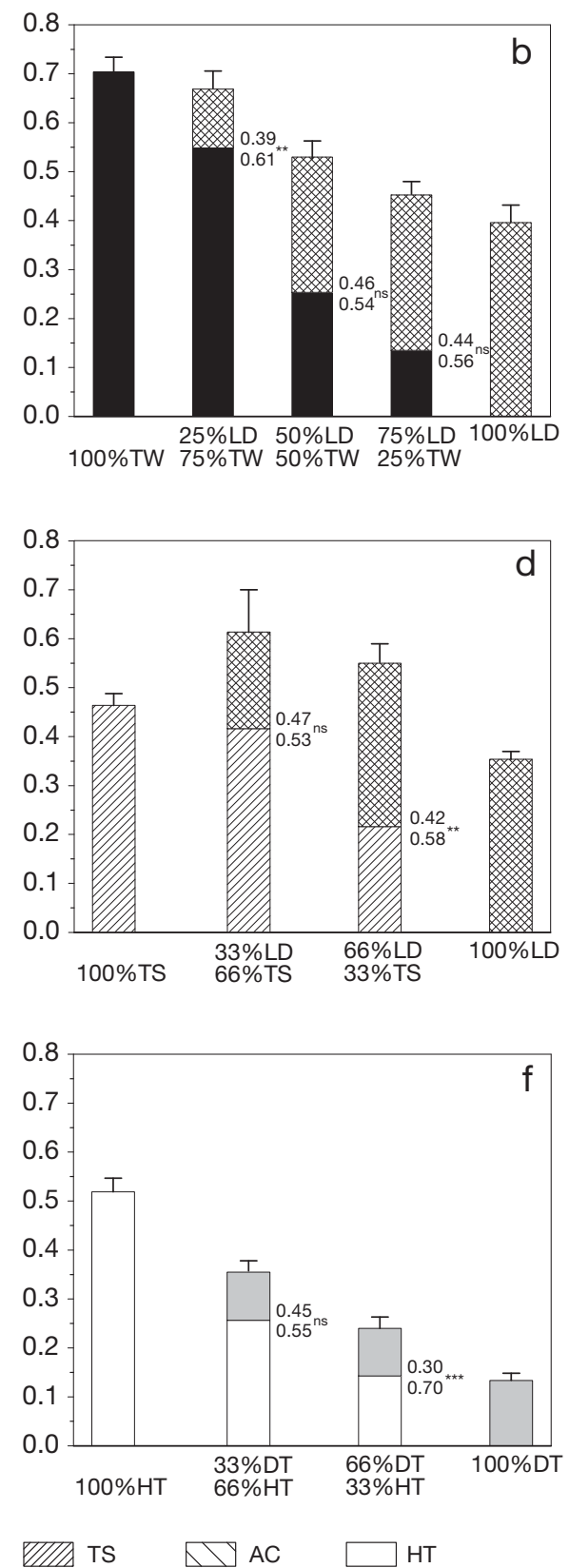

Fig. 1. Temora longicornis. Carbon-based ingestion rates, $I\left(\mu \mathrm{g} \mathrm{C} \mu \mathrm{g}^{-1}\right.$ female $\left.\mathrm{C} \mathrm{d}^{-1}\right)$ of $T$. longicornis feeding on the phytoplankton species mixtures offered in the 6 experiments, (a) TW + DT, (b) TW + LD, (c) LD + DT, (d) TS + LD (e) AC + TS and (f) HT + DT. Different shading patterns in the bars correspond to the phytoplankton types TW, DT, LD, TS, AC and HT (see Table 2 for full species names). The selection index $\alpha$ is shown next to the bars of the mixtures they represent, where $\alpha>0.5$ indicates positive selection; whiskers: $+1 \mathrm{SE}$ of the total carbon ingestion. Results of $t$-tests representing the difference of $\alpha$ from 0.5 are indicated with: ns: nonsignificant difference ${ }^{* *}: \mathrm{p}<0.001{ }^{* * *}: \mathrm{p}<0.0001$ 
its availability (selection index $\alpha<0.5$ ). Therefore, $T$. longicornis showed a significant preference for Thalassiosira weissflogii, Leptocylindricus danicus and Heterocapsa triquetra (33HT/66DT) over D. tertriolecta, but in the $66 \mathrm{HT} / 33 \mathrm{DT}$ diet mixture an $\alpha$-value of 0.45 was not significantly different from 0.5 . No selection was detected when $L$. danicus and $T$. weissflogii were offered together, except for a positive selection for $T$. weissflogii with the 75TW/25LD mixture. T. longicornis selected Tetraselmis suecica over Amphidinium carterii, as well as over L. danicus, in the 33TS/66LD mixture.

In the 19 food treatments Temora longicornis ingested very different proportions and concentrations of the 5 PUFAs of interest (PUFA 5 ; Fig. 2a). The PUFA ingestion is a combination of the fatty acid composition of the different phytoplankton types offered (Fig. 2b, Table 2) and the ingestion rates of each of these diets (selection). The lowest total $\mathrm{PUFA}_{5}$ ingested was on a
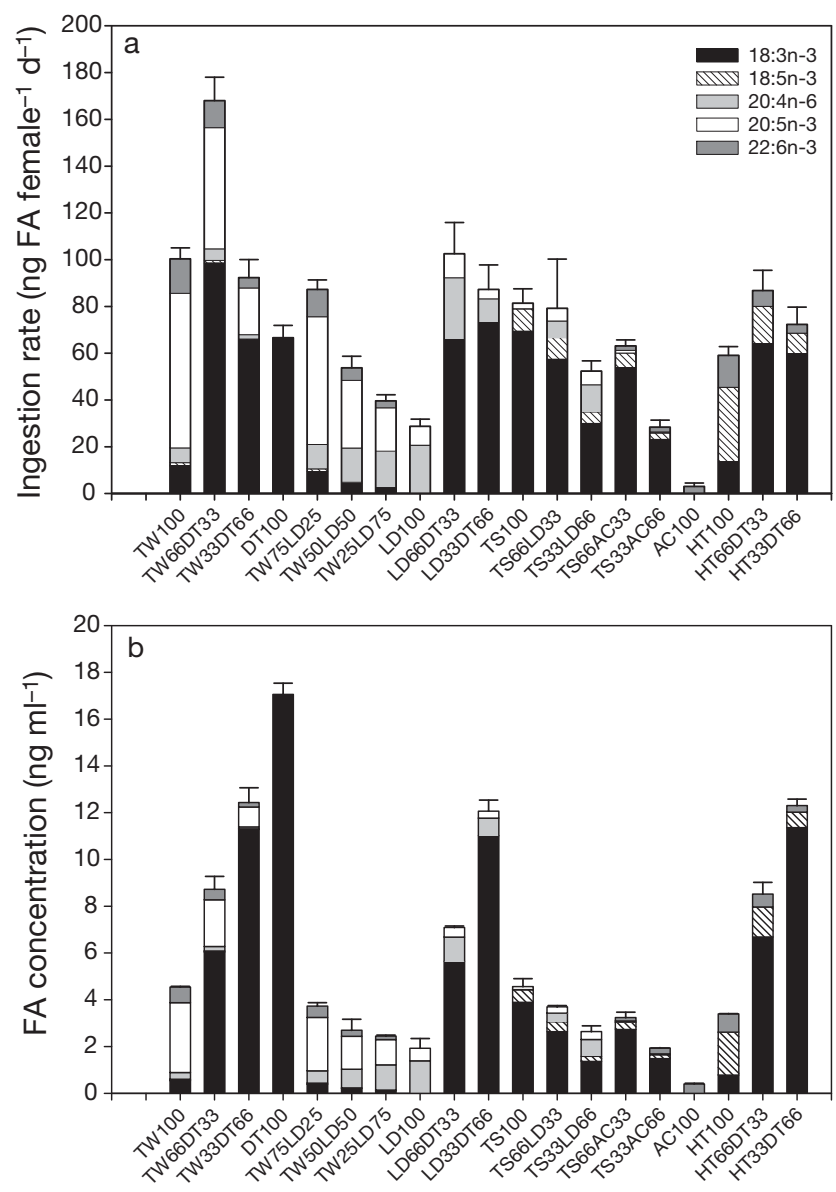

Fig. 2. Temora longicornis. (a) Ingested specific fatty acids (pg FA female $\mathrm{f}^{-1} \mathrm{~d}^{-1}$ ), (b) concentration of the 5 fatty acids, 18:3n$3,18: 5 n-3,20: 4 n-6,20: 5 n-3$ and 22:6n-3, offered. The shading patterns in the bars indicate the 5 fatty acid types, and the 19 treatments specified in Table 3 are labelled on the $x$-axis
$100 \%$ AC diet (3 ng PUFA female $^{-1} \mathrm{~d}^{-1}$ ), and the highest, with the TW66/DT33 mixture (168 ng PUFA 5 female $^{-1} \mathrm{~d}^{-1}$ ). There was a significant difference between the ingested $\mathrm{PUFA}_{5}$ in the 19 treatments (1way ANOVA, $\left.F_{18}=18.14, \mathrm{p}<0.001\right)$. The composition of these ingested fatty acids was tested in the model.

\section{Reproduction}

EPRs varied depending on the phytoplankton mixture offered, ranging from 1 to 20 eggs female ${ }^{-1} \mathrm{~d}^{-1}$, being significantly highest when a diet of TW alone was offered (Fig. 3a). The difference between the 2 highest rates, with TW and 75TW/25LD diets (Fig. 3b), was highly significant (2-way ANOVA: $F_{1,70}=185.9$, $\mathrm{p}<0.001$ ). Acclimation to the food offered took $2 \mathrm{~d}$, and all statistical analyses were performed on rates observed on Days 3 to 9. Out of 171 pairs, a significant difference was found between 137 pairs (Holm-Sidak multiple post hoc comparison, $\mathrm{p}<0.001$ ).

Hatching declined with time on most but not all of the treatments; after $9 \mathrm{~d}$ of incubation it ranged from 15 to $81 \%$ (Fig. 3c,d). The highest hatching percents (65 to $81 \%$ ) were achieved on the diet mixtures 33TW/ 66DT, 66HT/33DT, 75TW/25LD and 66TW/33DT (Fig. 3d) and on the single diet 100AC (Fig. 3c), while the lowest hatching rates (15 to $20 \%$ ) were achieved on the diet mixtures 25TW/75LD, 66TS/33LD, 33TS/66LD and 50TW/50LD (Fig. 3d). Statistical comparisons of the different treatments were done on measurements from Days 6 and 10, and, of 171 pairs, significant differences were found between 37 pairs (Holm-Sidak multiple post hoc comparison, $\mathrm{p}<0.001$ ).

\section{Female composition}

The total fatty acid content and the $\mathrm{PUFA}_{5}$ ratios in the females are shown in Fig. 4. The data is composed of 1 to 3 measurements of 24 to 40 females each, but due to the lack of variance estimate in many of the averages, these cannot be statistically compared. Generally, the fatty acid content ranged from 0.03 to $1.8 \mu \mathrm{g}$ female $^{-1}$ (Fig. 4a). The females from the initial culture appeared to have a higher PUFA content $(0.4 \mu \mathrm{g}$ female $^{-1}$ ) compared to females from the experimental treatment. Some females appeared to be drained of fatty acids after $9 \mathrm{~d}$ on the diet mixtures. Of the 5 fatty acids of interest $\left(\mathrm{PUFA}_{5}\right)$, the initial ratio was composed of ca. $20 \%$ of $18: 3 n-3,40 \%$ of $20: 5 n-3$ and $40 \%$ of $22: 6 n-3$. The factions of these fatty acids were quite variable at the end of the experiments depending on the food treatments offered (Fig. 4b). The dietary fatty acid 18:5n-3 did not appear in the females, and females 

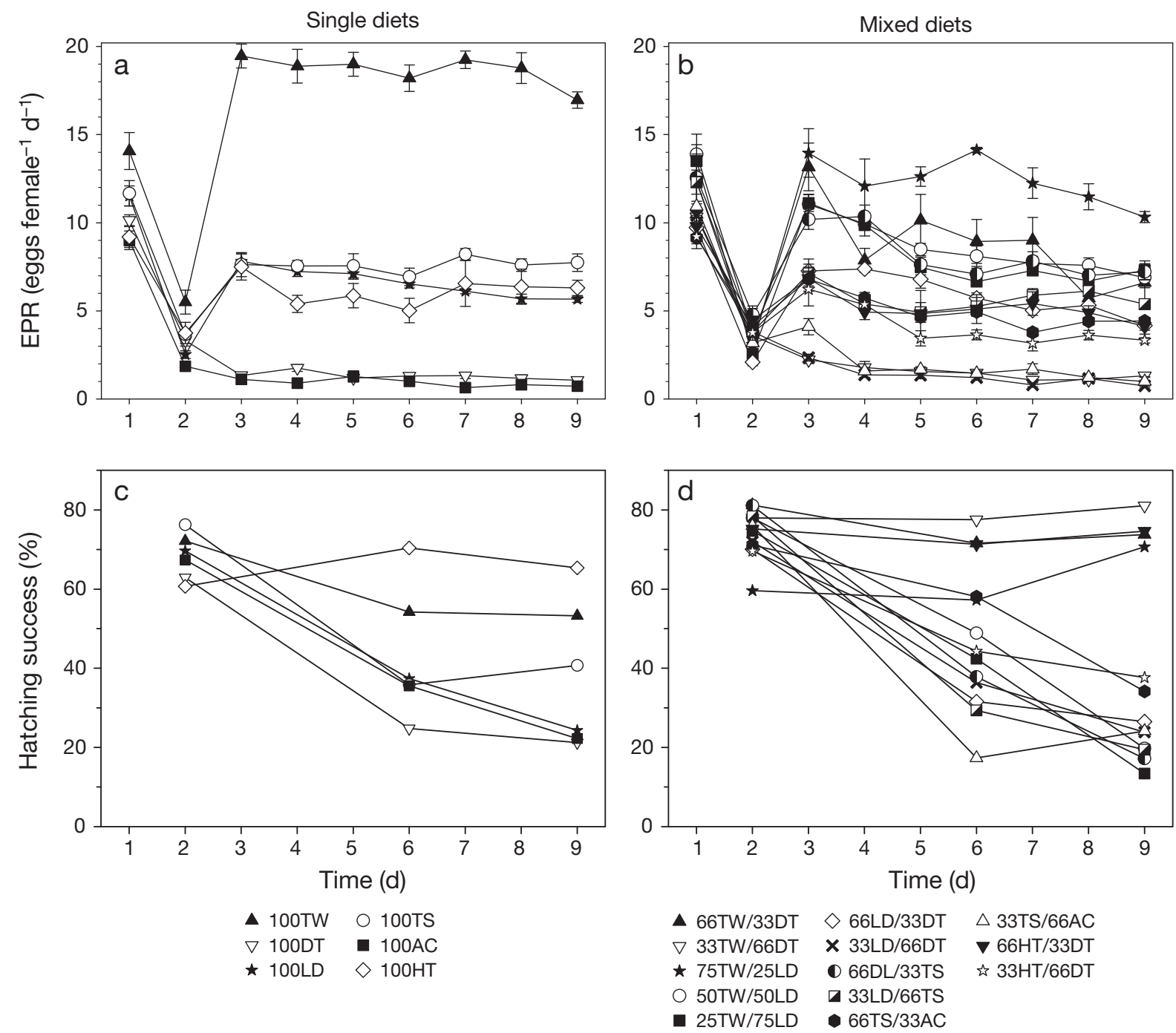

Fig. 3. Temora longicornis. Egg production rates (EPR, eggs female $\mathrm{e}^{-1} \mathrm{~d}^{-1}, \pm 1 \mathrm{SE}$ ) in (a) single-diet and (b) mixed-diet experiments, and percent hatching success of the eggs in (c) single diet and (d) mixed diet experiments over $9 \mathrm{~d}$

from 4 diet mixtures only had 22:6n-3 out of the 5 PUFAs of interest at the end of the experiment. The fatty acid 20:5n-3 was not measurable in the females in 9 of the 19 treatments.

\section{The model}

Results from the multiple regression model are shown in Table 4 . In each of the 3 production parameters tested (egg production, hatching success, nauplii production), a parsimonious and significant model was found.

Egg production was highly correlated with the amount of the fatty acid 20:5n-3 ingested (singular $R^{2}=$ $0.66, p=0.006$ ) in combination with carbon (combined $\mathrm{R}^{2}=0.76$ ). In contrast, hatching success showed a sig- nificant but weaker dependence on the fatty acids 22:6n-3, 18:3n-3 and 18:5n-3 (combined $\mathrm{R}^{2}=0.65$ ), but no relationship with total ingested carbon. Nauplii production was highly correlated with the fatty acid 22:6n3 (singular $\mathrm{R}^{2}=0.79$ ) together with total carbon (combined $\mathrm{R}^{2}=0.87$ ). Fig. 5 illustrates the results for the best model of the 2 most significant parameters for egg production: hatching and naupliar production.

\section{DISCUSSION}

All organisms need several types of nutritional components for successful growth (see e.g. Harrison 1990). However, the apparent importance of these various nutritional components depends on the particular aspect of growth that is measured. Further, it is clear 

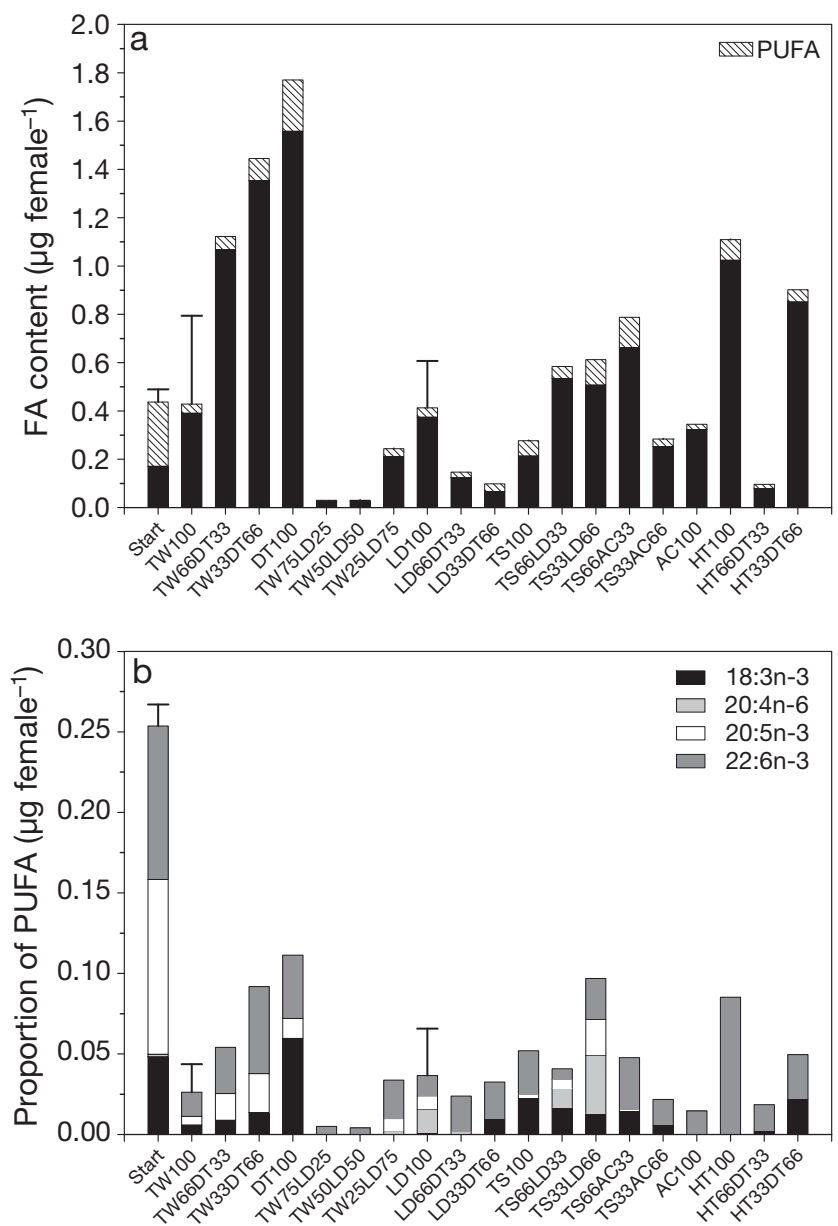

Fig. 4. Temora longicornis. Fatty acid content of females at the start of the experiment (start) and after $9 \mathrm{~d}$ in the 19 different treatments specified in Table 3. (a) Total fatty acids ( $\mu \mathrm{g}$ female ${ }^{-1}$ ), where the lighter shade indicates polyunsaturated fatty acids (PUFA) and the dark bars the non-PUFAs and (b) the proportion of specific fatty acids $18: 3 n-3,20: 4 n-6,20: 5 n-3$ and 22:6n-3 ( $\left.\mu \mathrm{g} \mathrm{female}^{-1}\right)$ in the PUFA fraction of the female

that various reproductive and growth aspects (gonad development, egg production, egg quality, naupliar and juvenile growth) have requirements for $>1$ nutritional component, and these may change during different stages of development. It has complicated nutritional studies that particular nutritional needs are not the same for these different growth phases. Reproduction involves maternal mobilization, biosynthesis and bioaccumulation of materials that are transferred to eggs (Harrison 1990). When the egg is fertilized, it has to be able to support the development of the embryo, e.g. for 2 naupliar non-feeding stages as in the case of Temora longicornis and most copepod species. The diet has to supply sufficient energy and nutrients to meet the reproductive cost of egg production, and the number of eggs produced is dependent on the quantity
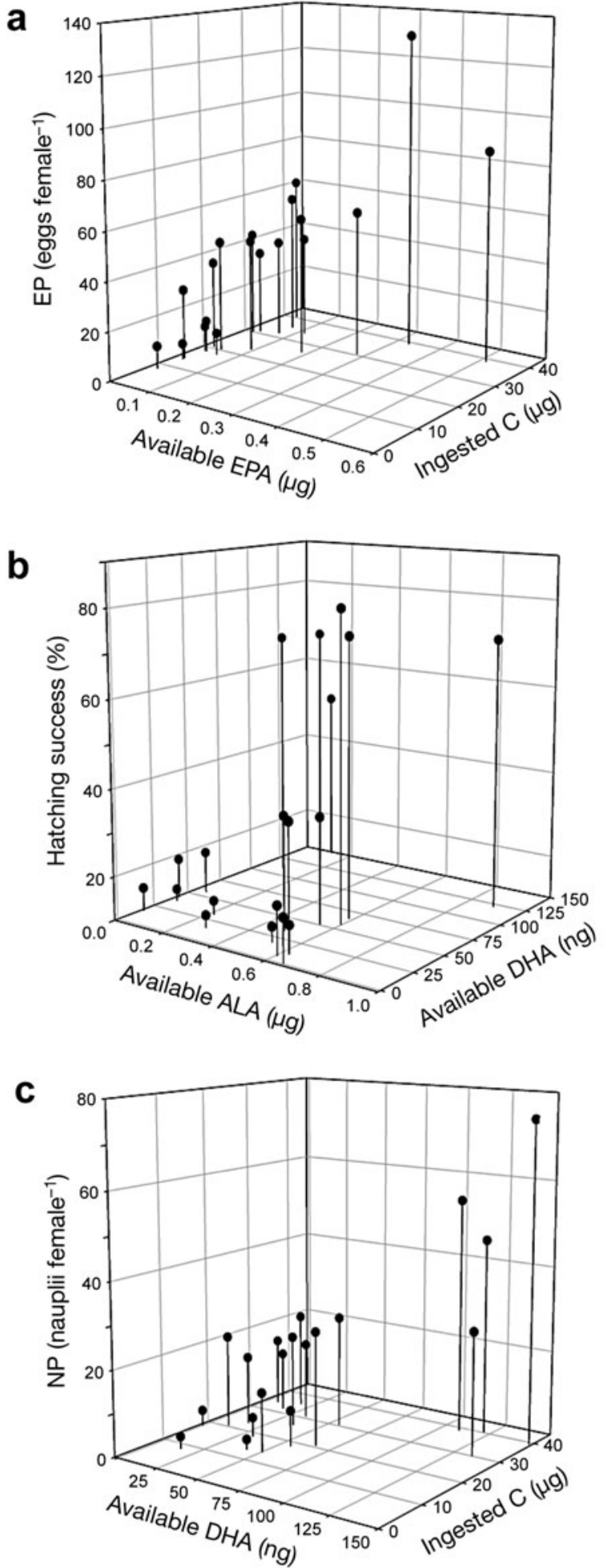

Fig. 5. Temora longicornis. Correlations of (a) cumulative egg production (EP, Day 3 to 9 of the experiment), (b) percent hatching success (Day 9) and (c) naupliar production (NP, Day 3 to 9 of the experiment) against the maternal and ingested fatty acids (available) and total ingested carbon $(\mu g)$, giving the best statistical fit (see Table 4). ALA: 18:3n-3 $(\mu \mathrm{g})$; EPA: 20:5n-3 ( $\mu \mathrm{g})$; DHA: 22:6n-3 (ng) 
Table 4. Results from multiple, stepwise regression on egg production (eggs female ${ }^{-1}$ ), total naupliar production (nauplii female ${ }^{-1}$ ) and hatching success (\%) against the maternal and ingested 5 fatty acids and total ingested carbon. The stepwise process selects only those variables (labelled 'in') that contribute to the best regression. Variables not in the regression are labelled 'out'. $\mathrm{R}^{2}$ : coefficient of determination of the multiple regression; df: degrees of freedom; $p$ : significance value of the multiple regression; $\mathrm{p}_{\mathrm{var}}$ : significance of the variable within the regression (asterisks indicate the most significant variables contributing to the model). For each variable in the model, 'F-to-remove' is the F-statistic for its coefficient within the regression; for each variable not in the model, ' $F$-to-enter' is the $F$-statistic that its coefficient would have if it were the next variable added in the regression

\begin{tabular}{|c|c|c|c|c|c|}
\hline & Variable & Status & $F$-to-remove & $F$-to-enter & $\mathrm{p}_{\mathrm{var}}$ \\
\hline \multirow{6}{*}{$\left(R^{2}=0.76, d f=16, p<0.001\right)$} & Total C & In & 13.7 & - & $0.002^{*}$ \\
\hline & $18: 3 n-3$ & Out & - & 0.048 & 0.829 \\
\hline & $18: 5 n-3$ & Out & - & 0.624 & 0.441 \\
\hline & $20: 4 n-6$ & Out & - & 1.187 & 0.292 \\
\hline & $20: 5 n-3$ & In & 9.4 & - & $0.007^{*}$ \\
\hline & $22: 6 n-3$ & Out & - & 3.338 & 0.086 \\
\hline Hatching success & Total C & Out & - & 0.991 & 0.335 \\
\hline$\left(\log _{10}\right.$ arcsine transformed) & $18: 3 n-3$ & In & 8.6 & - & $0.010^{*}$ \\
\hline \multirow[t]{4}{*}{$\left(\mathrm{R}^{2}=0.65, \mathrm{df}=15, \mathrm{p}=0.001\right)$} & $18: 5 n-3$ & In & 4.3 & - & $0.057^{*}$ \\
\hline & $20: 4 n-6$ & Out & - & 0.468 & 0.504 \\
\hline & $20: 5 n-3$ & Out & - & 0.002 & 0.970 \\
\hline & $22: 6 n-3$ & In & 17.5 & - & $<0.001^{*}$ \\
\hline Total naupliar production & Total C & In & 10.9 & - & $0.004^{*}$ \\
\hline \multirow[t]{5}{*}{$\left(\mathrm{R}^{2}=0.88, \mathrm{df}=16, \mathrm{p}<0.001\right)$} & $18: 3 n-3$ & Out & - & 0.371 & 0.551 \\
\hline & $18: 5 n-3$ & Out & - & 0.004 & 0.951 \\
\hline & $20: 4 n-6$ & Out & - & 0.086 & 0.773 \\
\hline & $20: 5 n-3$ & Out & - & 0.465 & 0.505 \\
\hline & $22: 6 n-3$ & In & 38.3 & - & $<0.001^{*}$ \\
\hline
\end{tabular}

and quality of the food (Jónasdóttir 1994). The eggs can vary greatly in size and fatty acid composition depending on the diet, resulting in great variation in hatching success (Pond et al. 1996). Successful hatching often seems to have different requirements than does egg production. This is well demonstrated when EPR and hatching are plotted against one another, where the general pattern seems to be that when EPR is high, hatching success is high, while at lower EPR, hatching can be quite variable (Jónasdóttir \& Kiørboe 1996, Shin et al. 2003). This pattern is also evident in our results (relationship not shown). In the same way, it should not be assumed that somatic growth and reproductive growth have the same requirements. This is one of the main misconceptions in the literature when discussing the nutritional needs for growth. The studies on nutritional requirements for somatic growth indicate that sterols and protein might be of more importance than specific fatty acids (Klein Breteler et al. 2005, Koski et al. 2006).

In the present study, we used mixtures of mediocre or poor diets to try to establish which fatty acids limit copepod egg production and egg quality and, consequently, naupliar production. The idea was to use nonartificially treated food (instead of fatty acid supplements) with different fatty acid profiles, reflecting various food mixtures, to simulate different ratios of some of the potentially important fatty acids. The 19 different phytoplankton mixtures gave a wide range in concentrations and ratios of the 5 fatty acids (Fig. $2 b$, Table 2) and resulted in very different proportions and concentrations of the fatty acids ingested (Fig. 2a). In agreement with some of the studies listed in Table 1, our results show the importance of the fatty acid 20:5n-3 for egg production, together with carbon. The fatty acid 20:5n-3 is one of the main membrane lipids and a precursor for eicosanoids, e.g. hormone activities. However, the direct pathway for this fatty acid in the copepod egg production process is not fully understood.

Because of large differences in the ingestion rates of the different diets ( 0.9 to $6 \mu \mathrm{g} \mathrm{C}$ female $\mathrm{e}^{-1} \mathrm{~d}^{-1}$ ), Temora longicornis may have been food limited in some of the treatments, resulting in the observed quantitative dependence. While carbon limitation could possibly be avoided by providing higher initial food concentrations, food selection and ingestion rates will always control the carbon availability for growth. The ingestion rates and residence time of food in the gut are dependant on the quality of the available food (Tirelli \& Mayzaud 2005). Egg production rates in the present study were highest on TW, at about 20 eggs female ${ }^{-1}$ $\mathrm{d}^{-1}$, while the expected maximum for the same size T. longicornis would be about 60 eggs female $\mathrm{e}^{-1} \mathrm{~d}^{-1}$ 
(S. H. Jónasdóttir unpubl. obs.). This indicates that some additional food limitation for egg production occurred even for the best diet tested.

Hatching success is an estimate of the quality of the eggs produced and was strongly associated with the ingestion and female contribution of the long-chain PUFA 22:6n-3 and, to a lesser extent, the 18:3n-3 and 18:5n-3 fatty acids. The first 2 fatty acids have previously been positively related to hatching success (Table 1). As for $20: 5 n-3,22: 6 n-3$ is metabolized to form docosanoids, a group of potent hormones that have been associated with neural functions in vertebrates. The 18:5n-3 fatty acid, here found in HT and TS, was not observed in females, and it is likely that it was directly metabolized. A second possibility is that it was elongated to 20:5n-3 and/or further desaturated to 22:6n-3. However, the ability to elongate and desaturate $18: 3 n-3$ to a 20 PUFA may be limited (Bell et al. 2007).

The combined coefficient of determination (Table 4) shows that $35 \%$ of the variance in hatching was not explained and indicates that some limiting variables were not taken into account in the measurements and subsequent model. These could, for example, be some specific sterols (Crockett \& Hassett 2005) that are important for membrane function and are precursors for many hormones, such as steroid hormones (Harrison 1990), and/or specific amino acids (Guisande et al. 2000). The total reproductive sum, i.e. the total naupliar production, was very well explained $\left(R^{2}=0.88\right)$ by ingested carbon and the fatty acid 22:6n-3 - the 2 factors that best explained EPR and hatching, respectively.

The contribution of maternal protein towards egg production is reported for some larger copepod species (Paraeucheta: Alonzo et al. 2000, 2001; Calanus: ReyRassat et al. 2002), but using the potential female reserves is, to our knowledge, a new approach in foodquality studies. The present study shows that the female selectively utilizes PUFAs (Fig. 4a) and especially 20:5n-3 (Fig. 4b). The female composition is otherwise related to the intake of the dietary fatty acids. In some treatments (e.g. $100 \%$ AC), the females were totally depleted of PUFAs, while non-PUFA fatty acids increased compared to values for the initial females (Fig. 4a). The magnitude of this female contribution is, however, not clear, and the importance of this contribution would require complete stoichiometric balance, where the fatty acid composition of eggs and faecal pellets would specifically have to be known.

The approach used in the present study is promising. Ultimately, however, the production and growth measured depend on the nutrient components fuelling the underlying physiological processes. These can come from the diet, but the maternal contribution through stored reserves may play a crucial role when essential nutrients are limiting. Therefore, to identify the underlying nutritional needs for reproduction, it is vital that the maternal contribution is taken into account. Observing a positive reproductive response when a suspected essential component is totally absent from the diet is no guarantee that that particular nutritional component is unimportant, if the organism can retrieve it from its own body reserves. Therefore, female condition and specific lipid accumulation is an important factor in reproductive success.

The present study shows the importance of certain long-chain fatty acids for successful reproduction in copepods and underlines that $>1$ fatty acid is important for the total reproductive process. The study also underlines that the nutritional need for making a viable egg is different from simply making an egg itself. Therefore, meeting nutritional needs for successful reproduction is a multi-tiered process. The ecological implication of these results may be that during phytoplankton blooms containing species rich in EPA (diatoms), Temora longicornis may produce many eggs with low or variable naupliar production. Later, phytoplankton succession of dinoflagellates high in DHA, and often in 18:5n-3, may result in lower egg production rates, but, due to higher hatching, the naupliar production is higher, resulting in similar reproductive output during the season.

It is apparent that one of the major shortcomings in many food-quality studies, including some of our own, is the black box approach, where correlations are made directly between the food available and reproduction. It is clear that food selection (ingestion) plays a critical role in availability of nutrient components for growth, and to obtain meaningful correlations between diet and growth, measurements of ingestion rates are essential.

Acknowledgements. The present study was funded by the Danish Research Agency Grant Number: 21-03-0487 to S.H.J. We thank P. Christiansen for assistance with fatty acid analysis, Dr. E. Toby for discussions and advice on statistics, and M. Koski and 4 anonymous reviewers for useful comments.

\section{LITERATURE CITED}

Alonzo F, Mayzaud P, Razouls S (2000) Egg-production dynamics, biochemical composition and hatching success of the subantarctic copepod Paraeuchaeta antarctica: laboratory studies. Mar Ecol Prog Ser 205:219-227

Alonzo F, Mayzaud P, Razouls S (2001) Egg production and energy storage in relation to feeding conditions in the subantarctic calanoid copepod Drepanopus pectinatus: an experimental study of reproductive strategy. Mar Ecol Prog Ser 209:231-242

Arendt K, Jónasdóttir SH, Hansen P, Gärtner S (2005) Effects 
of dietary fatty acids on the reproductive success of the calanoid copepod Temora longicornis. Mar Biol 146: 513-530

Bell M, Dick J, Anderson T, Pond D (2007) Application of liposome and stable isotope tracer techniques to study polyunsaturated fatty acid biosynthesis in marine zooplankton. J Plankton Res 29:417-422

Broglio E, Jónasdóttir SH, Calbet A, Jakobsen HH, Saiz E (2003) Effect of heterotrophic versus autotrophic food on feeding and reproduction of the calanoid copepod Acartia tonsa: relationship with prey fatty acid composition. Aquat Microb Ecol 31:267-278

Chesson J (1978) Measuring preference in selective predation. Ecology 59:211-215

Chesson J (1983) The estimation and analysis of preference and its relationship to foraging models. Ecology 64: 1297-1304

Crockett EL, Hassett RP (2005) A cholesterol-enriched diet enhances egg production and egg viability without altering cholesterol content of biological membranes in the copepod Acartia hudsonica. Physiol Biochem Zool 78: 424-433

Dutz J, Koski M, Jónasdóttir SH (2008) Copepod reproduction is unaffected by diatom aldehydes or lipid composition. Limnol Oceanogr 53:225-235

Ederington M, McManus G, Harvey H (1995) Trophic transfer of fatty acids, sterols, and triterpenoid alcohol between bacteria, a ciliate, and the copepod Acartia tonsa. Limnol Oceanogr 40:860-867

> Evjemo J, Reitan K, Olsen Y (2003) Copepods as live food organisms in the larval rearing of halibut larvae (Hippoglossus hippoglossus L.) with special emphasis on the nutritional value. Aquaculture 227:191-210

Evjemo JO, Tokle N, Vadstein O, Olsen Y (2008) Effect of essential dietary fatty acids on egg production and hatching success of the marine copepod Temora longicornis. J Exp Mar Biol Ecol 365:31-37

Frost B (1972) Effects of size and concentration of food particles on the feeding behavior of the marine planktonic copepod Calanus pacificus. Limnol Oceanogr 17:805-815

> Guisande C, Riveiro I, Maneiro I (2000) Comparisons among the amino acid composition of females, eggs and food to determine the relative importance of food quantity and food quality to copepod reproduction. Mar Ecol Prog Ser 202:135-142

Hansen PJ (1989) The red tide dinoflagellate Alexandrium tamarense: effects on behaviour and growth of a tintinnid ciliate. Mar Ecol Prog Ser 53:105-116

Harrison K (1990) The role of nutrition in maturation, reproduction and embryonic development of decapod crustaceans: a review. J Shellfish Res 9:1-28

Hassett R (2004) Supplementation of a diatom diet with cholesterol can enhance copepod egg-production rates. Limnol Oceanogr 49:488-494

Hassett R (2006) Physiological characteristics of lipid-rich 'fat' and lipid-poor 'thin' morphotypes of individual Calanus finmarchicus C5 copepodites in nearshore Gulf of Maine. Limnol Oceanogr 51:997-1003

Hazzard SE, Kleppel GS (2003) Egg production of the copepod Acartia tonsa in Florida Bay: role of fatty acids in the nutritional composition of the food environment. Mar Ecol Prog Ser 252:199-206

Ianora A, Miralto A, Buttino I, Romano G, Poulet S (1999) First evidence of some dinoflagellates reducing male copepod fertilization capacity. Limnol Oceanogr 44:147-153

> Jónasdóttir SH (1994) Effects of food quality on the reproduc-

Editorial responsibility: William Peterson,

Newport, Oregon, USA tive success of Acartia tonsa and Acartia hudsonica: laboratory observations. Mar Biol 121:67-81

Jónasdóttir SH, Kiørboe T (1996) Copepod recruitment and food composition: Do diatoms affect hatching success? Mar Biol 125:743-750

Jónasdóttir SH, Fields D, Pantoja S (1995) Copepod egg production in Long Island Sound, USA, as a function of the chemical composition of seston. Mar Ecol Prog Ser 119:87-98

Jónasdóttir SH, Gudfinsson H, Gislason A, Astthorsson O (2002) Diet composition and quality for Calanus finmarchicus egg production and hatching success off southwest Iceland. Mar Biol 140:1195-1206

> Jónasdóttir SH, Trung N, Hansen F, Gärtner S (2005) Egg production and hatching success in the calanoid copepods Calanus helgolandicus and Calanus finmarchicus in the North Sea from March to September 2001. J Plankton Res 27:1239-1259

Klein Breteler WCM, Schogt N, Baas M, Schouten S, Kraay G (1999) Trophic upgrading of food quality by protozoans enhancing copepod growth: role of essential lipids. Mar Biol 135:191-198

Klein Breteler WCM, Schogt N, Rampen S (2005) Effect of diatom nutrient limitation on copepod development: role of essential lipids. Mar Ecol Prog Ser 291:125-133

Kleppel G, Burkart C (1995) Egg production and the nutritional environment of Acartia tonsa: the role of food quality in copepod nutrition. ICES J Mar Sci 52:297-304

Kleppel G, Burkart C, Houchin L (1998) Nutrition and the regulation of egg production in the calanoid copepod Acartia tonsa. Limnol Oceanogr 43:1000-1007

> Koski M, Klein Breteler W, Schogt N, Gonzalez S, Jakobsen H (2006) Life-stage-specific differences in exploitation of food mixtures: diet mixing enhances copepod egg production but not juvenile development. J Plankton Res 28: 919-936

Lee HW, Ban S, Ando Y, Ota T, Ikeda T (1999) Deleterious effect of diatom diets on egg production and hatching success in the marine copepod Pseudocalanus newmani. Plankton Biol Ecol 46:104-112

Menden-Deuer S, Lessard E (2000) Carbon to volume relationships for dinoflagellates, diatoms, and other protist plankton. Limnol Oceanogr 45:569-579

Peters J, Dutz J, Hagen W (2007) Role of essential fatty acids on the reproductive success of the copepod Temora longicornis in the North Sea. Mar Ecol Prog Ser 341: 153-163

Pond D, Harris R, Head R, Harbour D (1996) Environmental and nutritional factors determining seasonal variability in the fecundity and egg viability of Calanus helgolandicus in coastal waters off Plymouth, UK. Mar Ecol Prog Ser 143:45-63

Rey-Rassat C, Irigoien X, Harris R, Head R, Carlotti F (2002) Egg production rates of Calanus helgolandicus females reared in the laboratory: variability due to present and past feeding conditions. Mar Ecol Prog Ser 238:139-151

Shin K, Jang M, Jang P, Ju S, Lee T, Chang M (2003) Influence of food quality on egg production and viability of the marine planktonic copepod Acartia omorii. Prog Oceanogr 57:265-277

Støttrup J, Jensen J (1990) Influence of algal diet on feeding and egg-production of the calanoid copepod Acartia tonsa Dana. J Exp Mar Biol Ecol 141:87-105

Tirelli V, Mayzaud P (2005) Relationship between functional response and gut transit time in the calanoid copepod Acartia clausi: role of food quantity and quality. J Plankton Res 27:557-568

Submitted: October 17, 2008; Accepted: February 19, 2009

Proofs received from author(s): April 20, 2009 